\title{
Choosing Union Representation: The Role of Attitudes and Emotions
}

\author{
Adrienne E. Eaton, Sean E. Rogers, Tracy F. H. Chang, and Paula B. Voos*
}

\begin{abstract}
In the U.S., most unions are recognized by a majority vote of employees through union representation elections administered by the government. Most empirical studies of individual voting behavior during union representation elections use a rational choice model. Recently, however, some have posited that voting is often influenced by emotions. We evaluate competing hypotheses about the determinants of union voting behavior by using data collected from a 2010 representation election at Delta Air Lines, a U.S.-based company. Multiple regression results provide some support for both the emotional choice model (with feelings toward the union being of much more importance than feelings toward the employer) and the older rational choice framework (with both union instrumentality perceptions and pre-existing attitudes being especially important).
\end{abstract}

*Adrienne E. Eaton is professor of labor studies and employment relations at Rutgers University. Sean E. Rogers is assistant professor of management at New Mexico State University. Tracy F. $\mathrm{H}$. Chang is associate professor of labor studies and employment relations at Rutgers University. Paula B. Voos is professor of labor studies and employment relations at Rutgers University. Please contact Professor Adrienne E. Eaton (eaton@work.rutgers.edu) for further information. 


\section{Introduction}

Throughout the English-speaking world, unions have suffered declining membership for some time, a situation that has only been exacerbated by the onset of the "Great Recession" in 2009 and an aftermath of high unemployment in which it was not always evident how unions could improve economic outcomes for workers. Unions are struggling with how to organize in this climate and how to appeal to unorganized employees - often one who is younger, technology-literate, and unfamiliar with, or even skeptical about, unions. In the United States most unions are certified through official government-run processes of representation elections ${ }^{1}$, despite some experimentation with other processes (Eaton \& Kriesky, 2001). Union recognition elections have also been part of the landscape in the UK since the passage of the Employment Relations Act in 1999 although elections have not developed as the dominant mode of recognition they are in the U.S. (Central Arbitration Committee, 2013). Clearly unions need to understand what sways an individual's decision in this context.

Considerable research in the U.S. has identified predictors of employees' support for unionization, voting intention, and actual voting behaviors in union certification elections (Barling, Kelloway, \& Bremermann, 1991; Blader, 2007; Catano, 2010; Deshpande \& Fiorito,

\footnotetext{
1 The National Labor Relations Board (NLRB) administers elections in much of the private sector and the National Mediation Board (NMB) administers elections in the railway and airline industries, the Federal Labor Relations Authority administers elections for federal government employees, and state government agencies generally administer elections for state and local government employees in state that permit collective bargaining in the public sector (many states do not). There are important differences in the election processes but they are not particularly relevant to this study, which involves an election run by the NMB - one that involves all the members of a particular "class or craft" (e.g. an occupation) in an individual employer. The NMB election process at one time required that a majority of all individuals in a craft or class vote for union representation before certifying a union, but that rule was changed before the election studied here. In the election we studied, as in NLRB elections, a simple majority of voters determined the outcome.
} 
1989; Fiorito \& Young, 1998; Friedman, Abraham, \& Thomas, 2006; Goeddeke \& KammeyerMueller, 2010; Hemmasi \& Graf, 1993; Hills, 1985; Martinez \& Fiorito, 2009; Premack \& Hunter, 1988). Interestingly, a comparable research literature has not developed in the U.K. Most of the existing research employs a rational choice theory in predicting an individual's tendency to vote for unionization - if an individual perceives greater benefits than costs, then he or she is more likely to vote for a union. Within this rational choice framework, an individual's perception of prospective union instrumentality, particularly in one's own workplace, is key to his or her decision to vote for or against union in a union certification election (Deshpande \& Fiorito, 1989).

In recent decades, economists have been concerned with the limitations of the rational choice model and have been increasingly emphasizing the role of emotions in economic transaction, decision making, and behavior (Vohs, Baumeister, \& Loewenstein, 2007). In the area of union voting research, some researchers have begun to examine the role of emotions, such as fear of reprisal, fear of conflict, distrust with the management, and satisfaction with the union, in affecting an employee’s tendency to vote for unionization (Catano, 2010; Cohen \& Hurd, 1998; Farber \& Saks, 1980; Godard, 2008; Hemmasi \& Graf, 1993).

Most recently, Martinez and Fiorito (2009) argue that perceived union instrumentality is a limited predictor of voting intention. They find that "general feelings toward unions" and "general feelings about employers" are primary forces motivating an individual's intent to vote for union representation and that "feelings toward unions" is the most important predictor. Martinez and Fiorito (2009) contribute to the literature by demonstrating employees' "feelings" play an important role in guiding their union voting intentions. However, their study is limited in several ways. First, they use the measure of "union voting intentions," the likelihood that one 
will vote for the union in a hypothetical union election held on the survey day, instead of the reported vote in an actual union election. Second, they use secondary survey data and so were not able to shape the survey questions closely to test their theory. Third, the emotion is measured by a single-item - how one rates his or her "feelings" toward the union (or the employer) from very negative to very positive on a five-point scale.

Our study will update and enhance current understanding of determinants of an individual's vote for union representation and contribute to the literature in several ways. First, our study offers a comprehensive examination of the factors, including emotional factors, that influence employees' vote for union representation. Second, our study is the first attempt to measure emotions and their effect on unionization vote. Third, our study involves a real-life union certification election among employees of one of the world's largest passenger air carriers - Delta Air Lines.

In the following sections, we will first provide the context of the present study by providing a brief review of the corporate as well as unionization history at Delta Air Lines. This context will establish the significance and uniqueness of the present study and form the foundation underlying our research. Following the context of our study, we will present the theoretical approaches to an individual's decision to vote for or against unionization, followed by a review of the empirical research in this area. Next, we will introduce our research methods and report our finding. Then, we will discuss the implications and limitations of our study and suggest directions for future research.

\section{Context for the Study}

Delta Air Lines, headquartered in Atlanta, Georgia, is one of the world's largest passenger air carriers, serving more than 162 million passengers in 2010 (Bureau of 
Transportation Statistics, 2013). The company has a workforce of more than 80,000 employees and operates a fleet of 722 aircrafts (Delta Air Lines, 2013). Delta provides flights to 331 destinations in 61 countries, and had annual revenues of over \$35 billion in 2011.

From its start as a crop-dusting company, Delta maintained an employment relations policy and corporate culture that some have termed “enlightened paternalism” (Kaufman, 2013). Employees enjoyed above average wages, job security, and a sense of belonging to the "Delta family," which in turn fostered a willingness to provide exceptional customer service and to be highly productive. Delta pilots did choose union representation in the mid-1930s. Nonetheless, they were treated as "part of the family" by Delta management, and most employees bought into the corporate culture of Delta. A vivid example of the Delta employee "buy-in" came in 1982, when, during a very difficult financial period in the company's history, employees banded together to purchase their employer a new Boeing 767 airplane at cost of $\$ 30$ million. $^{2}$

Delta experienced rapid growth and expansion both before and after the deregulation of the U.S. airline industry in 1978. Much of this was via merger and acquisition activity. In the early 1990s Delta experienced unprecedented economic pressures and in 1991, it cut nonunion wages and salaries. The unionized pilots, who refused to take concessions, experienced layoffs. After even further cuts in 1994, there were murmurs about Delta's "breaking of the covenant" (Kaufman, 2013). When the airline recovered financially, it managed to restore pay at the end of the 1990s. In 2000-2001, the airline pilots union demanded even higher compensation; the pilots union negotiated with Delta and received a pilots pay that was $2 \%$ above the average of all airlines, signaling to other employees that union representation might pay off.

\footnotetext{
2 http://www.airlinereporter.com/2010/10/the-spirit-of-delta-air-lines-the-gift-of-aboeing-767/. We thank an anonymous referee for suggesting that we add this example.
} 
The events of September 11, 2001 initiated dramatic problems for all airlines, including Delta. After years of depressed demand for air service nationwide and globally, Delta filed for Chapter 11 bankruptcy in September 2005. At the time of its filing, several other major U.S. air carriers were also operating under bankruptcy protection, including United Airlines, US Airways, and Northwest Airlines. As before, the Delta family culture both cushioned the shock and became less convincing to some employees. Delta Air Lines emerged from bankruptcy in 2007, and a year later acquired Minneapolis-based Northwest Airlines to create what became, at the time, the world's largest passenger airline.

From 2008 to 2011, Delta faced a series of union representation elections, the largest of which involved the flight attendants of the merged airline in 2010. Airline mergers and acquisitions around the world have historically presented significant challenges to firms in terms of workforce integration. Kole and Lehn (1999, p. 273) noted that airline "industry experts have commented on the general difficulty of integrating workforces in airline mergers," and they themselves concluded based on their in-depth analysis of USAir's acquisition of Piedmont Aviation that "the integration of labour is more problematic in airline mergers than it is in less heavily unionized, less regulated mergers”. A longstanding issue in the U.S. has been the integration of company seniority lists, and the post-merger economic well-being of employees from each company. Practically every U.S. airline merger in the past decade has been characterized by labour integration problems of one form or another.

It is under this fragile merger and acquisitions environment - arguably the most challenging among all U.S industries and sectors - that Delta Air Lines and Northwest Airlines joined forces in 2008. At this time, flight attendants at Delta were not organized but Northwest Airlines were represented by the Association of Flight Attendants (AFA) of the Communication 
Workers of America (CWA). Under the U.S. Railway Labor Act, which covers the airline industry, the entire "class or craft" in the merged airline would have to either be represented or not represented. The number of flight attendants at Delta at the time of the merger was significantly larger than the number at Northwest $(12,806$ vs. 7,111). Our study focuses on the 2010 union certification election for this entire class of flight attendants at Delta after the merger.

\section{Theoretical Approaches to the Decision to Vote for a Union}

A common theoretical framework for the decision to vote for a union can be characterized as a rational choice model in which an individual votes "yes" if the estimated benefits of unionization are greater than the estimated costs. The benefits and costs could be evaluated in a strictly financial sense, but more commonly a psychologically-enhanced version of this model is employed in which non-money costs and benefits are evaluated at the equivalent financial value placed on them by the individual (e.g. a 70\% probability that I will have more voice with unionization is evaluated by me as being worth $\$ 5000$ ). That is, individuals are assumed to evaluate the following basic equation where Prob is the probability, Ben is the benefit, and Cost is the cost:

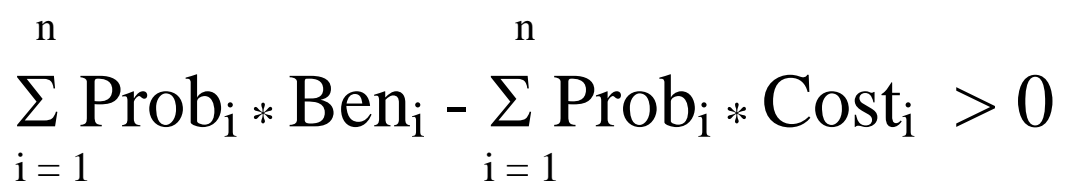

In this framework, union instrumentality is defined as the union's predicted ability of increasing the probable benefits of unionization and reducing the probable costs. One version of this model that is more psychological and sociological is implicit in many studies. First, some psychological models contend that individuals look for alternatives to existing situations when 
they are dissatisfied. For instance, most employees are not actively searching for other jobs; the dissatisfied are more likely to search. So in this framework, individuals who are more dissatisfied at work are the ones who begin to evaluate union instrumentality - the degree to which they believe the union will change an initially unsatisfactory situation. Sociology enters with its insight that individuals rarely estimate probabilities or value particular working conditions as isolated individuals. Those who live in communities in which unions are common and are seen as legitimate, those who are from union families, those who have been in a union in the past, and those who believe unions are generally a good thing (a pro-union orientation) are more likely to have higher estimated benefits or lower estimated costs, other things equal.

This model has been useful in many respects as a basis for research even though it is not strictly testable (in the sense that psychological valuation of costs/benefits are always inferred to be sufficient to drive any observed choice). However, it is subject to a different objection - that it simply does not capture the actual process many people use to make decisions, which is not so much a rational one of weighing the probable costs and benefits, but instead relies, at least in part, on "gut feelings" or emotion. We defer discussion of that alternative theory to later in the paper.

\section{Empirical Research on the Decision to Vote for a Union and Hypotheses}

Considerable research has studied the predictors of employees’ voting intentions and actual voting behaviors in union certification elections, although none of these have involved surveys conducted since the start of the Great Recession. These studies have documented a comprehensive list of factors emerging from the theories discussed above: demographic and family history, economic and working conditions, employer and organizational characteristics, occupational and job attributes, perceptions and attitudes toward unions and employers, and 
recently feelings and emotions toward unions and employers (Barling, Fullagar, \& Kelloway, 1992; Barling et al., 1991; Blader, 2007; Catano, 2010; Friedman et al., 2006; Godard, 2008; Goeddeke \& Kammeyer-Mueller, 2010; Hills, 1985; Kelloway \& Watts, 1994; Premack \& Hunter, 1988). In the following section, we provide an overview of previous findings with regard to major predictors of an individual's vote for union representation and explain how they led to hypotheses for this study.

Economic, Organizational, and Occupational Characteristics

Poor economic and working conditions, or worsening conditions on the job, logically inspire people to form a union in hope of improving these conditions (Blader, 2007; Fiorito \& Young, 1998; Premack \& Hunter, 1988). Furthermore, employer practices, human resources policies, and job design also have been found to impact an individual's decision of voting for unionization. Occupational characteristics may also influence an individual's vote for union representation. Jobs with high autonomy and authority often sway individuals away from unionization (Godard, 2008; Hemmasi \& Graf, 1993). Industry may also matter given that unions are more common in some industries; Hills (1985) for instance, finds that pro-union attitudes are more prevalent among government and construction workers than workers in other industries.

While important, we don’t measure them directly. To some extent they are controlled for since all employees are in the same occupation and industry, and work for the same current employer. They likely did vary between Delta and Northwest and thus, our question on the airline of origin at least partly stands as a proxy for the different practices and policies of those two employers. Therefore, the influences of occupation and industry are held constant for the purposes of our study, which helps us to isolate the impact of other employee characteristics and attitudes. 


\section{Union Background and Experience}

Family socialization, union household (parent or spouse who are union members), and union network (including friends and co-workers) often produce union supporters. People who have union family members (parent or spouse) are more likely to be supportive of the union and vote for the union than those who do not have family members belonging to unions (Barling et al., 1991; Fiorito \& Young, 1998; Godard, 2008; Kelloway \& Watts, 1994). Friends and coworkers, who are union members or are supportive of the union, could also influence an individual's propensity to vote for the union (Godard, 2008). Hence, we hypothesize the following:

Hypothesis 1: Flight attendants who were union members in the past or who had union members in their family will be more likely to vote for AFA.

Further, those flight attendants who worked for Northwest previous to its merger with Delta have the most direct experience with this union and what it can (and cannot) achieve for members. While the relationship between Northwest Airlines flight attendants and their union may not have been completely harmonious over that airline’s decades of history, the flight attendants there continually chose union representation over non-representation. In contrast, flight attendants at Delta Air Lines have never voted affirmatively for union representation, no matter the state of their relationship with the firm and its management. Therefore, we propose the following hypothesis:

Hypothesis 2: Those who worked for Northwest prior to the merger would be more likely to vote for AFA.

Social Psychological Factors 
The literature suggests that workplace dissatisfaction (Friedman et al., 2006; Godard, 2008; Hemmasi \& Graf, 1993; Kochan, 1979; Premack \& Hunter, 1988), beliefs and attitudes toward unions (Fiorito \& Young, 1998; Godard, 2008; Hemmasi \& Graf, 1993), and perception of union instrumentality (Goeddeke \& Kammeyer-Mueller, 2010; Hemmasi \& Graf, 1993; Martinez \& Fiorito, 2009; Mellor, Golay, \& D., 2010; Premack \& Hunter, 1988) play a key role in solidifying votes for union representation.

Employees who are not content with various aspects of their job or employing organization have been found to desire union representation than those who are content (Barling et al., 1992; Friedman et al., 2006; Godard, 2008; Hemmasi \& Graf, 1993; Hills, 1985; Premack \& Hunter, 1988). Thus, we propose the following hypotheses:

Hypothesis 3: Flight attendants reporting greater job satisfaction will be less likely to vote for AFA.

Hypothesis 4: Flight attendants reporting higher levels of commitment to Delta will be less likely to vote for the union.

Perceived union instrumentality has been a major psychological predictor of union voting behavior (Mellor et al., 2010). Based on a rational choice framework, if one perceives that unions will be effective in improving wages, benefits, working condition, and a voice at work, he or she would more likely vote for unionization. Moreover, specific perception of union instrumentality in a workers' own job context is a better predictor than general perception of union instrumentality (Deshpande \& Fiorito, 1989; Hemmasi \& Graf, 1993). If workers believe that the union will be effective in improving their own wages, benefits, working conditions, and voicing concerns in their own workplace, they are more likely to vote for union representation. Hence, we propose: 
Hypothesis 5: Flight attendants who perceive that the AFA would be successful in changing conditions at Delta to be more likely to vote for AFA.

Since pilots are the only group at Delta that have been organized in the past, we also explored individuals perceptions of that experience; we posit that flight attendants who perceived the pilots union has having been successful at Delta would be more likely to vote for the union.

Hypothesis 6: Flight attendants who perceived that the Delta Air Lines pilots union has been successful at enhancing the employment conditions of pilots at Delta would be more likely to vote for AFA.

In addition to perception of union instrumentality, previous research also finds that general positive beliefs and attitudes toward unions contribute positive to a vote for the union (Fiorito \& Young, 1998; Friedman et al., 2006; Hemmasi \& Graf, 1993); Martinez \& Fiorito, 2009). If people think that labour unions are generally good for the society and that workers typically are better off with union representation, then they would more likely vote for the union than those have negative attitudes toward labour unions (Fiorito, 1992). Hence, we hypothesize the following:

Hypothesis 7: Flight attendants who have generally-positive attitudes toward unions would be more likely to vote for AFA.

\section{Emotional Factors}

The study of emotions raises conceptual and methodological challenges. There have been diverse, some contradictory, perspectives on the conceptualization of emotion and on the methodology of measuring emotions (Kemper, 1987; Scheff, 1983; Vohs et al., 2007). In the field of studying union voting behavior, various studies have incorporated emotion-laden 
constructs, such as fear of reprisal (Farber \& Saks, 1980; Godard, 2008), fear of conflict (Cohen \& Hurd, 1998), distrust with the management (Godard, 2008; Hemmasi \& Graf, 1993), and satisfaction with the union (Catano, 2010), but Martinez and Fiorito (2009) are the first to formally introduce the theory of emotions and put emotions on the center stage of their analysis.

What is emotion? According to Kemper (1987), emotions are "autonomic-motoriccognitive states.” How many emotions are there? Kemper (1987) responds that "the number of possible emotions is limitless.” However, Kemper (1987) stipulates four physiologically-based primary emotions - fear, anger, depression, and satisfaction. These emotions are "evolutionarily important, cross-culturally universal, ontogenetically early to emerge, and link empirically with important outcomes of social relations.” The secondary emotions include, but are not limited to, guilt, shame, pride, and so forth; they are acquired through socialization, and are derived from one of the primary emotions. Building on Kemper’s (1987) typology, Turner (1999) developed more labels of emotions and outlined four major forces that generate expectations and resulting emotions - demographic composition, structural position (e.g. power and status), cultural (e.g. social norms), and transaction (e.g. trade of resources and rewards).

“To arrive at a decision, people use both cognition and emotion” (Vohs et al., 2007). Neuroscientist Antonio Damasio (1994) argues that thought and emotion are intertwined. According to Damasio’s “somatic marker” theory, human thought is predominately made of images (i.e. symbolic and perception representation) and these images are linked to positive or negative feelings through previous experiences. If positive emotions (e.g., trust, happiness, or satisfaction) are associated with thought of an action or object, people would be prompted to take that action or be attracted to the object. In contrast, if negative emotions (e.g., anger, fear, anxiety) are associated with thought of an action or object, people would avoid taking the action 
or the object (Lakoff, 1999). Lakoff (1999) argues that somatic markers guide people to seek and filter information selectively and guide people to act accordingly even when the information is false.

Emotion has both cognitive and non-cognitive components ${ }^{3}$ (Bandelj, 2009; Vohs et al., 2007). Some researchers argue that emotion assists rational decision-making by shaping preferences and by overcoming limited information and uncertainty. Others argue that emotion serve as a "heuristic" for decision making - to make decision making easier, people judge an action or object by how they think about it as well as how they feel about it (Bandelj, 2009). Emotion can also have a physiological and bodily foundation - people make decisions based on their "gut' feeling or intuition (Bandelj, 2009).

This theory is relevant to understanding a number of earlier empirical findings with regard to why employees support, or fail to support a union. For instance, Godard (2008) notes that a significantly higher portion of Canadian workers would vote for the union if they could be assured that there would no reprisal from the employer. Cohen and Hurd (1998) argue that fear of conflict is the most reported reason why people would not join any employee organization, more important than fear of reprisal. Farber and Saks (1980) confirm that concerns over a possible deteriorating relationship between worker and supervisor persuade workers to vote against unionization. Hemmasi and Graf (1993) find that faculty’s distrust in their university administration leads to job discontent and a desire for union representation.

In this study, we test whether or not emotions have a separate impact on voting behavior after controlling for general pro-union attitudes, job satisfaction and other factors that likely

\footnotetext{
${ }^{3}$ We consider that emotions are different from attitudes. Emotions are subjective experiences of "autonomic-motoric-cognitive states" as proposed by Kemper (1989), while attitudes are cognitive appraisal and evaluation toward an object.
} 
correlate with emotions. We propose the following hypotheses:

Hypothesis 8: Flight attendants with greater positive feelings toward Delta would be less likely to vote for unionization.

Hypothesis 9: Flight attendants with greater positive feelings toward the AFA would be more likely to vote for unionization.

These two hypotheses are central ones to this paper. We do include demographic control variables but are not primarily interested in exploring their relationship to union voting.

\section{Demographic Control Variables}

We control for race, gender and length of time as a flight attendant. Race often has a significant effect on voting intentions as well as actual voting for union representation. Most studies show that African-Americans are more likely to have a positive view of unions and would more likely vote for union representation than white Americans (Barling et al., 1992;

Friedman et al., 2006; Godard, 2008; Hills, 1985). A variety of reasons have been postulated to explain that fact, ranging from greater dissatisfaction with conditions at work (given lower pay and less good jobs), to comfort with collective action, to the demonstrated success of unions in reducing discrimination in the workplace. In contrast to race, gender has a less conclusive effect on voting for union representation (Barling et al., 1992; Godard, 2008). The effect of gender is often attenuated when work related factors highly correlated with gender like occupation and earnings are taken into account in the analysis (Barling et al., 1992; Hemmasi \& Graf, 1993) as it is in our study. Some studies find older workers or those with more job tenure favor unions (Barling et al., 1992; Friedman et al., 2006) but the relationship tends to disappear when job characteristics are included in the analysis. 
Our study differs from earlier ones in this area because it is a particular group of employees who were involved in a single organizing campaign. We hope our findings will deepen understanding of the choice process of workers when confronted with deciding whether or not to actually vote for a particular union in a particular work context. Our fundamental perspective is that if emotions are demonstrably important, then it will tend to support the view that voting for or against a union is an emotional process as well as a rational one, and that while the rational choice framework is often convenient, it can also be misleading.

\section{Data Collection, Methods, and Measures}

\section{Methods}

In early 2011 an invitation to participate in an Internet-based survey was emailed to 13,002 Delta Air Lines flight attendants. ${ }^{4}$ This sample was comprised both of flight attendants who had worked for Delta, or for Northwest, prior to the 2008 Delta-Northwest merger, as well as others who were hired post-merger into the new Delta Air Lines. We collected the data from March to April 2011 and received 1498 valid surveys, for a response rate of $12 \%{ }^{5}$

\section{Measures}

Here we present how the variables are measured.

\section{The Dependent Variable}

\footnotetext{
${ }^{4}$ The list of personal emails was acquired by the union during the organizing campaign and was provided to use for the purpose of this research. The database encompassed both those assessed as "supporters" by the union as well as those who were not. The union asked us to conduct the survey independently and not inform them of the response of any particular individual; the union wanted to know why it had failed to be successful.

${ }^{5}$ This was explained in part by the fact there was only one wave of the survey, which was the result of adverse reactions to the survey invitation email by many in the population surveyed. The Institutional Review Board which supervised this project recommended that we not continue with data collection beyond the first wave of invitations. Thus, this response rate represents those individuals who responded to our first and only invitation.
} 
Vote for AFA is a dichotomous variable with vote for AFA (coded as 1 ) and did not vote for AFA (coded as 0). Because the dependent variable is categorical, we use logistic regressions in testing relationships with the independent variables.

\section{Demographics and Union Background}

Woman is a dichotomous variable. Race was broken into four dichotomous variables: White, Black, Asian, and Other Race. Years as a Flight Attendant is measured by the total years in the flight attendant occupation. Pre-Merger Delta Employee is measured by whether or not the respondent was a Delta employee prior to the Delta-Northwest merger. Union Past is measured by whether or not the respondent had ever been in a labour union before working for Delta or Northwest. Union Family is measured by whether or not anyone in the flight attendant's immediately family currently belonged to a union.

Attitudes about the Job and Employer

Job Satisfaction is measured by a scale of three items ${ }^{6}($ alpha $=.82)$ taken from Hackman and Oldham's $(1975,1980)$ general job satisfaction scale. An example item includes "Generally speaking, I am very satisfied with my job at Delta." Organizational Commitment $(\alpha=.82)$ is measured with items from Meyer, Allen, and Smith (1993). An example item includes "I would be very happy to spend the rest of my career with this organization.” Intention to Quit ( $\alpha=.77$ ) is measured using two items from Rusbult, Farrell, Rogers, and Mainous (1988). The items include "I have recently spent some time looking for another job” and "I often think about quitting.” All items for the scales mentioned above are listed in the Appendix.

Union Instrumentality and General Attitudes toward Unions

${ }^{6}$ Two of the items were negatively worded and were recoded. 
Several items are used to assess flight attendant perceptions of two different aspects of union instrumentality - (1) the instrumentality of the AFA in general, and (2) the instrumentality of the pilots union at Delta Air Lines - and attitudes toward unions in general. We considered a number of data reduction strategies for these measures, but ultimately decided to keep the scales separate for theoretical and conceptual reasons. ${ }^{7}$ The resulting scales had high internal reliability and were created by summing the items.

Perceived instrumentality of AFA is measured using three items $(\alpha=.89)$, an example of which is "From what I know about the Association of Flight Attendants (AFA), I believe it represents its members well.”

Perceived Instrumentality of Delta Pilot's Union is the flight attendant's impression of the instrumentality of the pilots union at Delta for Delta pilots $(\alpha=.96)$. The scale includes four items, two of which are general statements of the union's benefit to Delta's pilot, one of which talks about pay and the other, respect.

Positive Attitudes about Unions Generally is measured by an additive scale of eight items $(\alpha=.90)$. Some but not all of the item directly address union instrumentality. Examples of items are: "Unions are good for workers" and "Employees who work in unionized organizations are better off than those who don't have a union.” Respondents indicated their level of agreement with each of the questions related to these constructs of union instrumentality on a five-point Likert scale where 1 = "Strongly Disagree" and 5 = "Strongly Agree." In all of the scales discussed above, any items that were worded negatively were recoded. All items are listed in the Appendix.

${ }^{7}$ Exploratory factor analysis of all union attitude questions led to a two-factor solution. Although many of the questions loaded well on both factors, four questions about the instrumentality of the pilots' union at Delta loaded very poorly on the first factor and very highly on the second one. 


\section{Emotions toward Delta and AFA}

The measurement of emotions has been a major methodological challenge and thus controversial. There is no standardized measurement or scale that is applicable to all contexts or studies $^{8}$; measures and scales are developed based on the specific needs and approach of each study. In the context of studying unionization vote, our study is the first attempt to incorporate measurements of emotions and examine their effects on an employee's voting preference. We began by considering one of the primary emotions proposed by Kemper (1987) - fear.

Fear is the most relevant primary emotion and often evoked in union organizing. Fear during union organization, of both reprisal and conflict, has been well documented by Cohen and Hurd (1998) and Godar (2008). Therefore, we include measures of fear for the employer and the union: "I am afraid of Delta" and "I am afraid of AFA".

In later studies, Bandelj (2009) established that trust, and empathy that builds trust, are important to economic transactions, and Jasper (1998) established that trust and respect are important to political action and social movement. Employment involves economic transaction and unionization resembles collective political action, so we include measures of trust ("I trust Delta" and "I trust AFA") and measures of empathy ("I feel that Delta cares about me" and "I feel that AFA cares about me").

Bandelj (2009) further identified the effect of "affect" on an individual's decision to continue or withdraw from an economic transaction with another party - an individual decides to continue the economic transaction because he/she "simply likes" the other party. Since these emotions work at the non-cognitive level, people may not be able to articulate or justify their decision to continue or withdraw from economic transactions. Therefore, we include measures of

\footnotetext{
${ }^{8}$ The General Social Survey in the U.S. includes a scale of emotions with 18 items, but it is developed for a general social survey purpose (Heise \& Lively, 2004).
} 
such positive affect: "I like Delta” and "I like AFA".

Building on previous research, we included emotional components of liking, trust, fear, and empathy that are found to be influential in economic transaction, decision making, and behavior (Cohen \& Hurd, 1998; Godard, 2008; Hemmasi \& Graf, 1993; Vohs et al., 2007) in a simple additive scale. The specific questions related to emotions toward Delta were: "I like Delta," “I trust Delta,” “I am afraid of Delta” (reverse-coded), and "I feel that Delta cares about me.” The respondent rated his/her agreement on each statement on a five-point Likert scale with $1=$ "Strongly Disagree" and 5 = "Strongly Agree." The scale Positive Feelings toward Delta $(\alpha$ $=.91$ ) summed all four items.

Positive Feelings toward AFA was similarly measured, with a scale of four items. ( $\alpha$ $=.91)$. These items were: "I like AFA," "I trust AFA," "I feel that AFA cares about me," and "I am afraid of AFA" (reverse-coded). The scale had high internal reliability ( $\alpha=.92)$.

\section{Results and Discussion}

\section{Descriptive Statistics}

Zero-order correlations, means or frequencies, standard deviations, and scale reliabilities are presented in Table 1.We applied list-wise deletion of cases to deal with missing data for certain variables, resulting in a final sample size of 996 for subsequent analysis. The sample is heavily (and over-) weighted toward "yes" voters with almost 70\% reporting they voted for AFA; in the actual vote, only $47.9 \%$ recorded votes for AFA. ${ }^{9}$ This overrepresentation of prounion voters in our sample may be due to the fact that the union sponsored the survey; it may

\footnotetext{
${ }^{9}$ Forty-six of our respondents indicated they had chosen neither "AFA" or "no union" but had written in to their ballot the name of some other union; these respondents were omitted from our analyses. A similarly small portion of the voters in the population wrote in another union.
} 
also be the case that pro-union voters are more likely to respond to a survey about a union election. Nonetheless, we still had a substantial number (329, or 33\%) of "no" voters included in our analyses. To account for potential non-response bias, we over-weighted these "no" voter observations in our sample so that our subsequent results would more accurately mirror the population. ${ }^{10}$

Seventy-three percent of respondents identified as a woman, which tracks quite closely with the overall flight attendant population in the United States of $79.1 \%$ in 2007, according to Saenz and Evans (2009). An overwhelming majority of flight attendants were White (90\%). While we don't know how representative that is of the population at Delta, the overall flight attendant population was only $70 \%$ white (vs. $90 \%$ in our sample) and 14\% African American (vs. 3\% in our sample) in 2007 (Saenz \& Evans, 2009), suggesting African-Americans may be under-represented in our sample. The average tenure of flight attendants in our sample is 23 years, which is near the airline industry average of 24 years.

The sample was split between pre-merger Delta flight attendants (45\%) and Northwest flight attendants (55\%), with former Delta FAs being under-represented compared to the population. ${ }^{11}$ Forty-five percent reported that they had belonged to a union in the past, which is over-represented in our sample compared to the population. Family union membership was also higher than what we expected, with 29.\% indicating that someone in their immediate family (i.e., spouse or partner, parent, or child) currently belonged to a union.

Table 1 also presents descriptive statistics for our quasi-continuous variables, including job satisfaction, organizational commitment, intention to quit, multiple dimensions of perceived union instrumentality, union attitudes, and emotion scales.

${ }^{10}$ We thank one of the anonymous referees for pointing out the need for this procedure. ${ }^{11}$ Only three respondents were hired after the 2008 merger occurred. 
Logistic Regression Results.

Two logistic regressions were run predicting a "yes” vote for the AFA. The first - Model 1 - excludes the two emotions-related variables, while the second - Model 2, the "full model" includes emotions. The following discussion pertains to the fully-elaborated, second model.

In terms of demographics, the results show that senior flight attendants were more likely to vote for the union, and that Asians and those of other races (than White, Black, or Asian) were less likely to vote for the union. None of the other controls were statistically significant predictors of a "yes" vote for the AFA.

Hypothesis 1 predicted that people with personal union membership experiences, either through having formerly been a union member or having a family member currently in a union, would be more likely to vote for the AFA. Though the corresponding results in Model 2 (Member of union before Delta or Northwest, and Family member(s) in a union) move in the correct direction, neither of these variables were statistically significant in Model 2. Thus, H1 is not supported.

Hypothesis 2 predicted that pre-merger Northwest flight attendants would be more likely to vote for the AFA. This is strongly supported - Northwest flight attendants were twice as likely to vote for the AFA as pre-merger Delta flight attendants.

Hypotheses 3 and 4 predicted that greater job satisfaction (H3) and higher levels of organizational commitment to Delta (H4) would be negatively related to a "yes" vote for the AFA. As predicted, higher commitment to Delta made it less likely that a flight attendant would vote "yes" for the AFA. Thus, H4 is supported. However, contrary to our predictions, job satisfaction was positively related to a "yes” vote. Thus, H3 is not supported. 
Job satisfaction (and dissatisfaction, in particular) has strong theoretical reasons why it should affect union vote and many studies have found it to be important. Why is that not the case here? Why might it be that our initial hypothesis is rejected? It is hard to be certain, but perhaps the genesis of the union representation election in this situation matters. After all, it is quite different than is the usual case where a large number of employees become so dissatisfied that they seek out union representation. In contrast, this election occurred because the merger of these two airlines - one unionized before the merger, and another not unionized before the merger - necessitated a decision as to whether or not the entire "class or craft” of flight attendants would or would not be union represented. Those who had union experience at Northwest Airlines were much more likely to want to keep that representation than those who had not had it at Delta.

Hypotheses 5-7 examined several relationships between union perceptions and attitudes, and a "yes" vote for the AFA. As predicted, flight attendants who believed that the AFA could be successful at improving employment conditions at Delta (H5), and who had generally-positive views about unions (H7), were more likely to vote "yes” for the AFA. Thus, H5 and H7 are supported. However, H6 was not supported - flight attendants who felt that the Delta pilots union was successful in improving pilot conditions were not more likely to vote "yes” for the AFA.

In Hypothesis 8 we predicted that flight attendants with positive feelings toward Delta would be less likely to vote "yes” for the AFA. Our results support this hypothesis. Likewise, the findings also support our prediction in Hypothesis 9 that positive feelings toward the AFA would be more likely to result in “yes” votes for the AFA. Taken together, our findings concerning these two hypotheses shed new light on the importance of emotions in union voting decisions, 
above and beyond the classic elements the rational-choice models. To confirm the importance of the role of emotions, we also asked respondents to indicate their level of agreement with the statement "I voted based on my gut feelings". Over 56\% of the respondent agreed or strongly agreed with this statement. ${ }^{12}$

\section{Collinearity Checks}

Possible multicollinearity concerns were suggested by some high zero-order correlations in Table 1. To ensure that our logistic regression results are not threatened by such issues, we considered the Variance Inflation Factors (VIFs) of each variable entered into Model 2. Given accepted VIF rules of thumb (O’Brien, 2007) whereby individual variable factors greater than 10 indicate problematic multicollinearity, our predictor variables displayed VIFs smaller than seven. More than half the variables had factors smaller than two. Thus, we are confident that our findings are not marred by collinearity issues.

\section{Conclusion}

Overall, this study provides support for the emotional choice model but also validates aspects of the older rational choice framework (union instrumentality perceptions and attitudes toward unions). The significant effect of feelings toward unions on unionization vote suggests that a union involved in an organizing drive often should invest more resources in improving employee emotions and attitudes toward the particular union and beliefs about its instrumentality, rather than emphasizing what is wrong with the employer.

A further theoretical consideration for studying workers' vote for unionization is the distinct two systems of "the architecture of cognition" - "thinking” and "deciding” (or

\footnotetext{
12 It's interesting to note that no voters were significantly more likely to report they had voted based on their gut feelings.
} 
“reasoning” and "intuition”) (Kahneman, 2003). According to Kahneman (2003), reasoning is what we do when we compute a mathematic calculation while intuition is when we refuse to eat a piece of chocolate in a shape of cockroach, for example. Reasoning is done deliberately and with effort, while intuition is done automatically and spontaneously. Emotion is part of the intuition process but intuition can be carried out without an emotional component. Kahneman (2003) argues that most of our thoughts and actions rely on intuition rather than reasoning. The high percentage of respondents indicating they voted based on gut feelings would seem to support this. Future research may investigate which mode of cognition, reasoning versus intuition, is involved for workers' vote for unionization and what conditions trigger one mode over the other. It also seems to us that future theory and research exploring what is an emotion and what is an attitude could be very important.

Although our study improved upon previous studies, it has its own limitations. Our dependent variable was a self-reported vote which may be different from the actual vote and it was reported in the same survey as the attitudes so there may be some common method bias in our data. In our study, we include multiple indicators of emotions toward the employer and the union, which may be preferable to the single indicator used by Martinez and Fiorito (2009). However, our measure of emotions was taken some time after the vote for or again unionization had been cast so it may not be an ideal measure. This lag in time assumes a stable emotional state but emotions can be transitory and sensitive to internal bodily state and external stimuli (Bandelj, 2009). However, in response to our survey invitation, many Delta flight attendants expressed strongly feelings toward the organization drive one year after the vote. Thus, emotions were not fleeting in this unionization election. It is also the case that respondents might answer our emotion and attitudinal questions in ways that rationalize their own vote. We attempted to 
attenuate this possibility by asking about their vote at the end of the survey; however, future research might query voters closer to their actual vote in order to lessen any potential bias even further.

We would conclude that people chose both rationally and emotionally when they are deciding for or against union representation. The variable that actually mattered most here was personal experience - those who had been union represented at Northwest wanted to keep that representation and those that had not were more skeptical of the value of labour representation.

Our finding that attitudes and feeling toward the union play a significant role in the outcome of the union organizing campaign offers an unconventional insight for union organizing strategy. If unions can successfully create positive perceptions and feelings on the part of potential members toward the union, it will have a better chance of winning a representation election. Presumably, it would also have a better chance of succeeding in organizing them through a non-election process too. 


\section{References}

Bandelj, N. (2009). Emotions in economic action and interaction. Theory and Society, 38(4), 347-366.

Barling, J., Fullagar, C., \& Kelloway, E. K. (1992). The unionization process. In J. Barling, C. Fullagar \& E. K. Kelloway (Eds.), The Union and its Members: A Psychological Approach (pp. 30-69). New York: Oxford University Press.

Barling, J., Kelloway, E. K., \& Bremermann, E. H. (1991). Preemployment Predictors of Union Attitudes: The Role of Family Socialization and Work beliefs. Journal of Applied Psychology, 76(5), 725-731.

Blader, S. (2007). What Leads Organizational Members to Collectivize? Injustice and Identification as Precursors of Union Certification. Organization Science, 18(1), 108-126.

Bureau of Transportation Statistics. (2013). Total passengers on U.S. airlines and foreign airlines U.S. flights increased 1.3\% in 2012 from 2011, from http://www.rita.dot.gov/bts/press releases/bts016 13

Catano, V. M. (2010). Union members' attitudes and perceptions about their union: Winning a representational election following a merger of four hospitals. Economic and Industrial Democracy, 31(4), 579-592.

Central Arbitration Committee. (2013). Central arbitration committee annual report 2012-2013, from http://www.cac.gov.uk/media/pdf/5/s/The CAC Annual Report 20122013.pdf

Cohen, L., \& Hurd, R. W. (1998). Fear, conflict, and union organizing. In K. Bronfenbrenner, S. Friedman, R. W. Hurd, R. A. Oswald \& R. L. Seeber (Eds.), Organizing to Win: New Research on Union Strategies (pp. 181-196). Ithaca: ILR Press.

Damasio, A. R. (1994). Descartes' error: Emotion, reason, and the human brain. New York: Avon Books.

Delta Air Lines. (2013). Delta aircraft fleet Retrieved May 15, 2013, from http://www.delta.com/content/www/en US/about-delta/corporateinformation/aircraft-fleet.html

Deshpande, S. P., \& Fiorito, J. (1989). Specific and general beliefs in union voting models. Academy of Management Journal, 32(4), 883-897.

Eaton, A. E., \& Kriesky, J. (2001). Union organizing under neutrality and card check agreements. Industrial and Labor Relations Review, 55(1), 42-59.

Eisenberger, R., Huntington, R., Hutchison, S., \& Sowa, D. (1986). Perceived Organizational Support. Journal of Applied Psychology, 71(3), 500-507.

Farber, H. S., \& Saks, D. H. (1980). Why Workers Want Unions: The Role of Relative Wages and Job Characteristics. Journal of Political Economy, 88(2), 349-369.

Fiorito, J. (1992). Unionism and Altruism. Labor Studies Journal, 17(3), 19-34.

Fiorito, J., \& Young, A. (1998). Union Voting Intentions: Human Resource Policies, Organizational Characteristics, and Attitudes. In K. Bronfenbrenner, S. Friedman, R. W. Hurd, R. A. Oswald \& R. L. Seeber (Eds.), Organizing to Win: New Research on Union Strategies (pp. 232-246). Ithaca dn London: Cornell University Press.

Friedman, B., Abraham, S., \& Thomas, R. (2006). Factors related to employees' desire to join and leave unions. Industrial Relations, 45(1), 102-110.

Godard, J. (2008). Union formation. In P. Blyton, N. Bacon, J. Fiorito \& E. Heery (Eds.), The Sage Handbook of Industrial Relations (pp. 377-405). Los Angeles: Sage Publishing. 
Goeddeke, F. X., Jr., \& Kammeyer-Mueller, J. D. (2010). Perceived support in a dual organizational environment: Union participation in a university setting. Journal of Organizational Behavior, 31(1), 65-83.

Hackman, J. R., \& Oldham, G. R. (1975). Development of the job diagnostic survey. Journal of Applied Psychology, 60(2): 159-170.

Hackman, J. R., \& Oldham, G. R. (1980). Work Redesign. Reading, MA: Addison-Wesley Publishing Company.

Heise, D. R., \& Lively, K. J. (2004). Sociological Realms of Emotional Experience. The American Journal of Sociology, 109(5), 1109-1136.

Hemmasi, M., \& Graf, L. A. (1993). Determinants of faculty voting behavior in union representation elections: A multivariate model. Journal of Management, 19(1), 13-32.

Hills, S. M. (1985). The attitudes of union and nonunion male workers toward union representation. Industrial and Labor Relations Review, 38(2), 179-195.

Kahneman, D. (2003). Maps of Bounded Rationality: Psychology for Behavioral Economics. [Article]. American Economic Review, 93(5), 1449-1475.

Kaufman, B. E. (2013). Keeping the Commitment Model in the Air during Turbulent Times: Employee Involvement at Delta Air Lines. Industrial Relations: A Journal of Economy and Society, 52, 343-377.

Kelloway, K. E., \& Watts, L. (1994). Preemployment predictors of union attitudes: Replication and extension. Journal of Applied Psychology, 79(4), 631-634. Kemper, T. D. (1987). How Many Emotions Are There? Wedding the Social and the Autonomic Components. The American Journal of Sociology, 93(2), 263-289.

Kochan, T. A. (1979). How American workers view their unions. Monthly Labor Review, 102, 23.

Kole, S. R., \& Lehn, K. M. (1999). Deregulation and the adaptation of governance structure: The case of the U.S. airline industry. Journal of Financial Economics, 52(1), 79-117.

Lakoff, G. (1999). Philosophy in the Flesh: The Embodied Mind and its Challenge to Western Thought. New York: Basic Books.

Martinez, A. D., \& Fiorito, J. (2009). General Feelings Toward Unions and Employers as Predictors of Union Voting Intent. Journal of Labor Research, 30(2), 120-134. Mellor, S., Golay, L. M., \& D., T. M. (2010). The character of American workers: Psychological predictors of union interest as tools for American union practitioners. Employee Responsibilities and Rights Journal, 24(2), 129-144.

Meyer, J. P., Allen, N. J., \& Smith, C. A. (1993). Commitment to organizations and occupations: Extension and test of a three-component conceptualization. Journal of Applied Psychology, 78(4), 538-551.

O'Brien, R. M. (2007). A caution regarding rules of thumb for variance inflation factors. Quality and Quantity 41, 673-90.

Premack, S. L., \& Hunter, J. E. (1988). Individual unionization decisions. Psychological Bulletin, 103(2), 223-234.

Rusbult, C. E., Farrell, D., Rogers, G., \& Mainous, A. G. (1988). Impact of exchange variable on exit, voice, loyalty and neglect: An integrative model of responses to declining job satisfaction. Academy of Management Journal, 31(3), 599-627.

Saenz, R., \& Evans, L. (2009). The changing demography of U.S. flight attendants. Population Reference Bureau. 
Scheff, T. J. (1983). Toward Integration in the Social Psychology of Emotions. Annual Review of Sociology, 9, 333-354.

Turner, J. H. (1999). Toward a General Sociological Theory of Emotions. Journal for the Theory of Social Behaviour, 29(2), 133-162.

Vohs, K. D., Baumeister, R. F., \& Loewenstein, G. (2007). Do Emotions Help or Hurt Decision Making?: A Hedgefoxian Perspective: Russell Sage Foundation. 
Table 1 -- Correlations, Means or Frequencies, Standard Deviations, and Scale Reliabilities

\begin{tabular}{|r|r|r|r|r|r|r|}
\hline & & & \\
\hline
\end{tabular}




\section{Table 1 (continued)}

\begin{tabular}{|c|c|c|c|c|c|c|c|c|c|c|}
\hline & Variable Name & (8) & (9) & $(10)$ & (11) & $(12)$ & (13) & (14) & (15) & $(16)$ \\
\hline (1) & Female & & & & & & & & & \\
\hline (2) & Years as a flight attendant & & & & & & & & & \\
\hline (3) & Black & & & & & & & & & \\
\hline (4) & Asian & & & & & & & & & \\
\hline (5) & Other race (non-White, Black, or Asian) & & & & & & & & & \\
\hline (6) & Member of union before Delta or Northwest & & & & & & & & & \\
\hline (7) & Family member(s) in a union & & & & & & & & & \\
\hline (8) & Pre-Merger Delta employee & & & & & & & & & \\
\hline (9) & Job satisfaction (.82) & $.518^{* *}$ & & & & & & & & \\
\hline (10) & Organizational commitment (.82) & $.561^{* *}$ & $.791^{* *}$ & & & & & & & \\
\hline (11) & Intention to quit (.77) & $-.268 * *$ & $-.577^{* *}$ & $-.588^{* *}$ & & & & & & \\
\hline (12) & Perceived instrumentality of Delta pilot union (.96) & $-.418 * *$ & $-.628 * *$ & $-.656 * *$ & $.389 * *$ & & & & & \\
\hline (13) & Perceived instrumentality of the AFA-CWA (.89) & $-.463 * *$ & $-.633 * *$ & $-.672 * *$ & $.399 * *$ & $.784^{* *}$ & & & & \\
\hline (14) & Positive attitudes about unions in general (.90) & $-.532 * *$ & $-.731^{* *}$ & $-.778 * *$ & $.478 * *$ & $.775^{* *}$ & $.842 * *$ & & & \\
\hline (15) & Positive feelings toward Delta (.90) & $.498 * *$ & $.823^{* *}$ & $.836 * *$ & $-.571 * *$ & $-.729 * *$ & $-.717 * *$ & $-.828 * *$ & & \\
\hline (16) & Positive feelings toward AFA-CWA (.92) & $-.504 * *$ & $-.646 * *$ & $-.688 * *$ & $.418^{* *}$ & $.660 * *$ & $.849 * *$ & $.832 * *$ & $-.719 * *$ & \\
\hline (17) & Voted for AFA-CWA & $-.514^{* *}$ & $-.636 * *$ & $-.713^{* *}$ & $.409 * *$ & $.679 * *$ & $.760 * *$ & $.822 * *$ & $-.729 * *$ & $.780 * *$ \\
\hline & & & & & & & & & & \\
\hline \multicolumn{11}{|c|}{ Notes: ${ }^{* *}$ Correlation is significant at the 0.01 level (2-tailed). ${ }^{*}$ Correlation is significant at the 0.05 level (2-tailed). $\mathrm{N}=996$. Listwise } \\
\hline \multirow{2}{*}{\multicolumn{11}{|c|}{$\begin{array}{l}\text { deletion of missing data. The internal reliabilities of scales are in parent } \\
\text { quasi-continuous variables, and percentages for dihotomous variables. }\end{array}$}} \\
\hline & & & & & & & & & & \\
\hline
\end{tabular}


Table 2 - Logistic Regression Analyses Predicting a Yes Vote for the AFA-CWA

\begin{tabular}{|c|c|c|c|c|}
\hline & Mode & & Model & \\
\hline & $\begin{array}{r}\text { (emotion vo } \\
\text { exclude }\end{array}$ & ables & (full moc & \\
\hline & $B$ & S.E. & $B$ & S.E. \\
\hline Job satisfaction & $0.114^{* *}$ & 0.065 & $0.244 * * *$ & 0.079 \\
\hline Organizational commitment & $-0.243 * * *$ & 0.052 & $-0.19 * * *$ & 0.060 \\
\hline Intention to quit & -0.078 & 0.067 & -0.095 & 0.070 \\
\hline Perceived instrumentality of Delta pilot union & 0.000 & 0.044 & 0.033 & 0.053 \\
\hline Perceived instrumentality of the AFA-CWA & $0.585^{* * *}$ & 0.083 & $0.247^{* *}$ & 0.102 \\
\hline Positive attitudes about unions in general & $0.189 * * *$ & 0.027 & $0.130 * * *$ & 0.030 \\
\hline Positive feelings (emotions) toward Delta & -- & -- & $-0.184 * * *$ & 0.068 \\
\hline Positive feelings (emotions) toward AFA-CWA & -- & -- & $0.301 * * *$ & 0.055 \\
\hline Female & -0.064 & 0.282 & -0.063 & 0.301 \\
\hline Years as a flight attendant & $0.025 *$ & 0.013 & $0.029 * *$ & 0.014 \\
\hline Black & -1.005 & 0.752 & -1.112 & 0.732 \\
\hline Asian & -0.750 & 0.605 & $-1.199 *$ & 0.677 \\
\hline Other race (non-White, Black, or Asian) & $-1.176 * *$ & 0.508 & $-1.246 * *$ & 0.550 \\
\hline Member of union before Delta or Northwest & 0.260 & 0.253 & 0.181 & 0.270 \\
\hline Family member(s) in a union & 0.298 & 0.268 & 0.189 & 0.289 \\
\hline Pre-Merger Delta employee & $-0.800 * * *$ & 0.271 & $-0.773 * * *$ & 0.293 \\
\hline Constant & $-8.688 * * *$ & 1.396 & $-7.452 * * *$ & 1.536 \\
\hline$N$ & 996 & & 996 & \\
\hline Cox and Snell R-Square & 0.64 & & 0.65 & \\
\hline Nagelkerke R-Square & 0.85 & & 0.87 & \\
\hline$* * * p \leq .01, * * p \leq .05, * p \leq .10$ & & & & \\
\hline
\end{tabular}




\section{Appendix}

\section{Items measuring attitudes and emotions (all scoring on a 5-point Likert scale from "Strongly Disagree" to "Strongly Agree” unless otherwise noted)}

\section{$\underline{\text { Job Satisfaction }}$}

Generally speaking, I am very satisfied with my job at Delta. Most of my co-workers are satisfied with their jobs at Delta. I would not recommend Delta as a good place to work to friends and family. (Reversecoded)

\section{Organizational Commitment}

I would be very happy to spend the rest of my career at Delta I really feel as if this Delta's problems are my own I do not feel a strong sense of "belonging" to Delta (Reverse-coded) I do not feel like "part of the family” at Delta (Reverse-coded)

\section{Intention to Stay}

I have recently spent some time looking for another job (Reverse-coded)

I often think about quitting (Reverse-coded)

\section{Attitudes Toward Unions Generally}

Unions reduce job security. (Reverse-coded)

Unions interfere with good relations between companies and workers. (Reverse-coded)

Unions are good for workers.

Unions play an important role in society.

Employees who work in unionized organizations are better off than those who don't have a union.

Union representation is not worth what it costs in union dues. (Reverse-coded)

Rate your feelings toward labour unions in general. (Very positive to very negative) Overall, how effective do you think labour unions are these days in improving wages, benefits, and working conditions for their members? (Very effective to very ineffective)

\section{Instrumentality of AFA}

From what I know about the Association of Flight Attendants (AFA), I believe it represents its members well.

AFA has not raised pay or benefits much at other airlines. (Reverse-coded) Overall, how effective do you think AFA would have been in improving wages, benefits, and working conditions for their members? (Very effective to very ineffective) 


\section{Instrumentality of Pilots Union at Delta}

Delta pilots are better off being in a union.

Management respects Delta pilots more because they are unionized.

Being in a union has been beneficial to the careers of Delta pilots.

Delta pilots would earn more and have better work rules if they were not in a union.

(Reverse-coded)

\section{Emotions Toward Delta}

I like the new, post-merger Delta.

I trust Delta.

I feel that Delta cares about me.

I am afraid of Delta. (Reverse-coded)

\section{Emotions Toward AFA}

I like AFA.

I trust AFA.

I feel that AFA cares about me.

I am afraid of AFA. (Reverse-coded) 